\title{
5G: Past and Future
}

\author{
Seizo Onoe \\ NTT DOCOMO, INC and DOCOMO Technology, Inc., Japan \\ E-mail:onoe@nttdocomo.com
}

Received 3 February 2018;

Accepted 15 March 2018

\begin{abstract}
$5 \mathrm{G}$ is gathering momentum and becoming a sort of boom. In this paper, the history of mobile communications is reviewed and what $5 \mathrm{G}$ will create is discussed with the background of the $5 \mathrm{G}$ boom. To gain more insight into $5 \mathrm{G}$, the economics of $5 \mathrm{G}$ are also discussed, clarifying concerns from myths about 5G. Lastly the predictions are presented being derived from the two laws defined by the author: the law of previous generations' boom just before the next and the law of great success only in even-numbered generations.
\end{abstract}

Keywords: Mobile communications, 5G, LTE, 6G, Economics.

\section{Introduction}

$5 \mathrm{G}$ is stimulating people's imagination and expectations for a new world that it may bring about by the year 2020. 5G is aimed at meeting a wide range of requirements such as further enhanced mobile broadband, massive connections and extremely long battery life for Internet of Things (IoT), and reliable critical communications with low latency. Furthermore, it is highly expected to invent new business models and ecosystems across the industries. $5 \mathrm{G}$ discussion is gathering momentum and so heated that it is becoming a sort of boom, which is sometimes generating unintended misconceptions and myths.

Journal of ICT, Vol. 5_3, 265-276. River Publishers

doi: $10.13052 /$ jicts $2245-800 X .534$

This is an Open Access publication. (c) 2018 the Author(s). All rights reserved. 
This paper is based on the keynote presentation given by the author at the IEEE 5G Summit Tokyo held in September 2017. The presentation started with how $5 \mathrm{G}$ was booming by counting the number of buzz words on the headlines of the daily news of Mobile World Congress (MWC) to show the term "5G" has been No. 1 in recent years. The $5 \mathrm{G}$ boom is addressed in the subsequent sections.

In this paper, first the history of mobile communications is reviewed to predict the future. Next, what $5 \mathrm{G}$ would create is discussed with the background of the $5 \mathrm{G}$ boom, which is followed by the discussion on the $5 \mathrm{G}$ economics to clarify the concerns from myths about 5G. Lastly, predictions are introduced being derived from the two laws that the author defined. One is the law of previous generations' boom just before the next and the other is the law of great success only in even-numbered generations.

\section{History of Mobile Communications Technologies}

The mobile communications industry has the history of technological transitions, where a new generation of technologies emerged every decade from $1^{\text {st }}$ generation to $4^{\text {th }}$ generation and this is expected to be repeated for the $5^{\text {th }}$ generation as shown in Figure 1. Note that, in this chronological table, each horizontal row represents each decade.

As shown in this figure, some activities including research for a new generation of technologies started just after the previous generation was launched, some outcomes were achieved within a few years and finally the new generation was launched almost 10 years later.

The history repeated from $1 \mathrm{G}$ to $4 \mathrm{G}$ and is likely happen to $5 \mathrm{G}$ as well. However, some differences are observed with $5 \mathrm{G}$.

Around 2013, 5G discussions were started with the term " $5 \mathrm{G}$ " and it became a boom as discussed in the introduction section. The term " $5 \mathrm{G}$ " has spread like wildfire. This is different from the state of $4 \mathrm{G}$ in early $2000 \mathrm{~s}$, when some outcomes were already achieved from $4 \mathrm{G}$ research; DOCOMO succeeded in $100 \mathrm{Mbps}$ data transmission in the outdoor field experiments in 2003 and 1 Gbps data transmission achieved in 2004. At that time, however, in the early days of $3 \mathrm{G}, 3 \mathrm{G}$ was in a tragic situation in terms of business and not well accepted in the market. From this experience, DOCOMO learnt the importance of a smooth path to the next generation and proposed the concept of "Super 3G." The Super 3G concept was designed with an intention to first evolve $3 \mathrm{G}$ and then build $4 \mathrm{G}$ on top of the evolved $3 \mathrm{G}$ in order to provide a 
smooth path to $4 \mathrm{G}$. DOCOMO called the evolved $3 \mathrm{G}$ by the name it created "Super 3G" [1]. Although DOCOMO's goal was 4G, to say the least, no one was interested in $4 \mathrm{G}$ at that time; frankly speaking, people did not like the term 4G. In fact, when a 3GPP study item that later became today's 4G LTE was proposed by DOCOMO and other 25 co-source companies in December 2004[2], the study item document included neither the term 4G nor LTE; it touched upon the term "long-term evolution," but just as a general expression. This study item finally became the today's 4G LTE standard.

The following story used to be a secret but it is not anymore since it is more than a 10-year-old story and already has been mentioned in other presentation opportunities.

A slide for an internal use is shown in Figure 2 and it was one of the slides the author used for initiating the LTE standardization in a meeting with an influential vendor. This slide was created before March 2004. It presented what would happen in the future, and actually the things happened exactly as it shows: the standardization started in December 2004, the specifications were approved in 2007 and the development was completed in 2009. This slide had precisely predicted what actually happened.

This proves authors' ability to correctly predict the mobile communications market. Based on this proof of ability to predict, the author makes new predictions in Section 5.

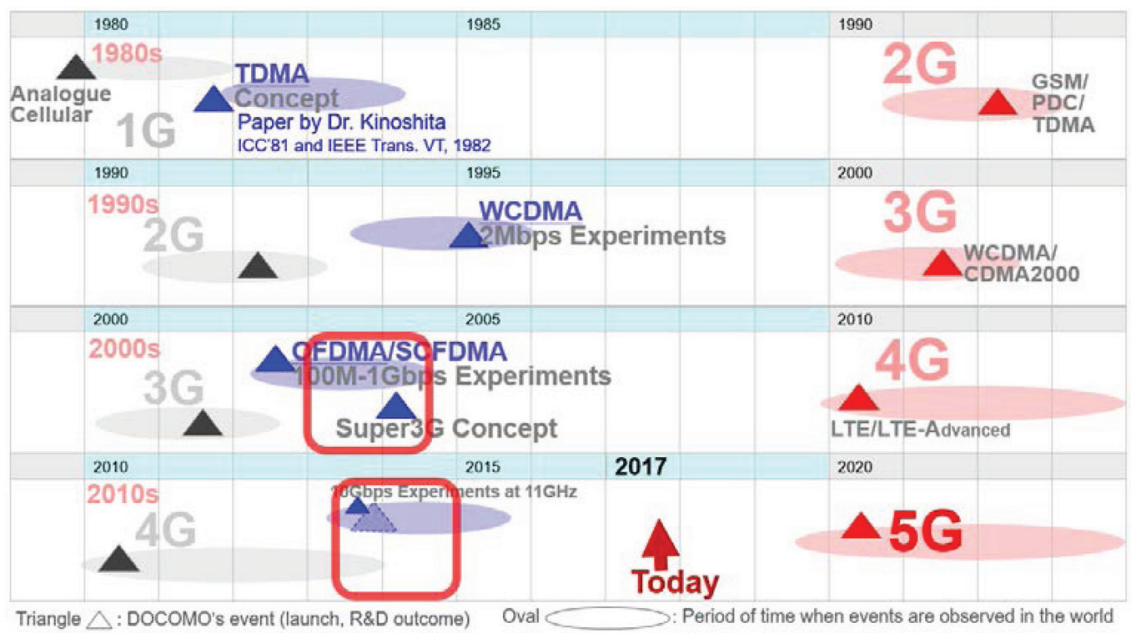

Figure 1 History from $1 \mathrm{G}$ to $4 \mathrm{G}$ and the Next. 


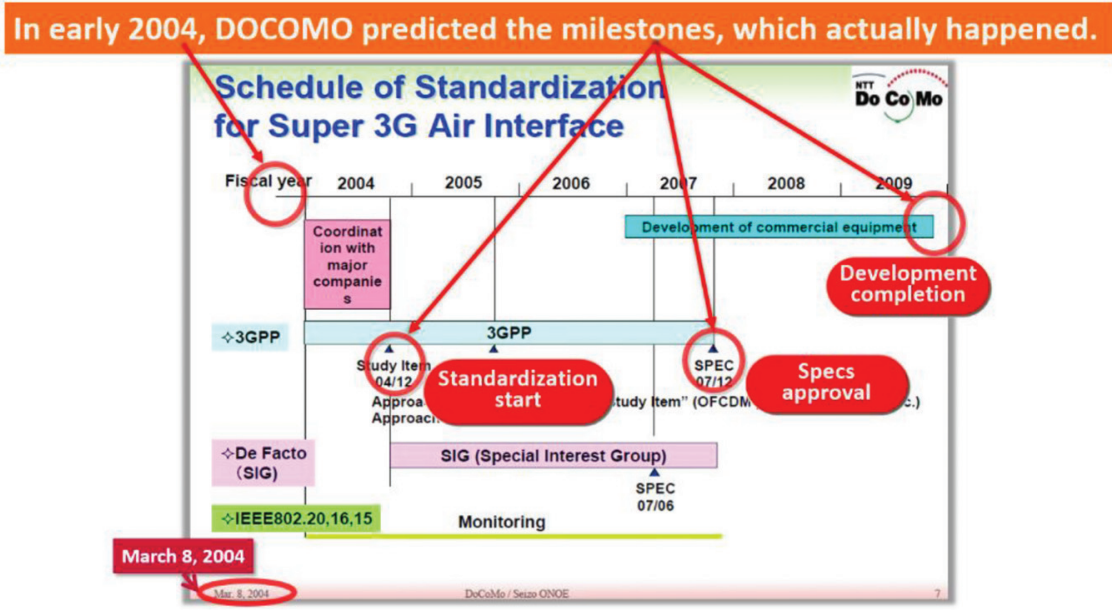

Figure 2 A Slide used for initiating the LTE standardization.

\section{What 5G Creates}

$5 \mathrm{G}$ is characterized by three features concerning capabilities and use cases: enhanced mobile broadband; massive machine type communications; and ultra-reliable, low-latency communications. DOCOMO made a video that shows typical $5 \mathrm{G}$ use cases and what $5 \mathrm{G}$ will provide and create by taking advantage of these three key features. The $5 \mathrm{G}$ features the author explained during the presentation were shared as a common understanding with other speakers in the previous sessions.

Another aspect was also brought into focus in the presentation. 5G has been a kind of boom started in recent years as described in the introduction. The author felt irritated with this 5G boom in many occasions, where people were talking about $5 \mathrm{G}$ even though what they discussed had nothing to do with 5G. This prompted the creation of the slide shown in Figure 3, which was shared in some presentation opportunities. This slide was fairly well received by the audience. There were many favourable comments posted in SNSs with its photos.

A friend of the author took a picture of the author presenting a slide of SNS posts on the podium. The friend proposed that the author use the picture for a next presentation and let someone take a picture of the slide with the author again and repeat it. The picture in Figure 4 was taken during the author's presentation at the IEEE 5G Summit Tokyo and includes ten or more nested images of the author. The number of presentations shows global interest in 5G. 


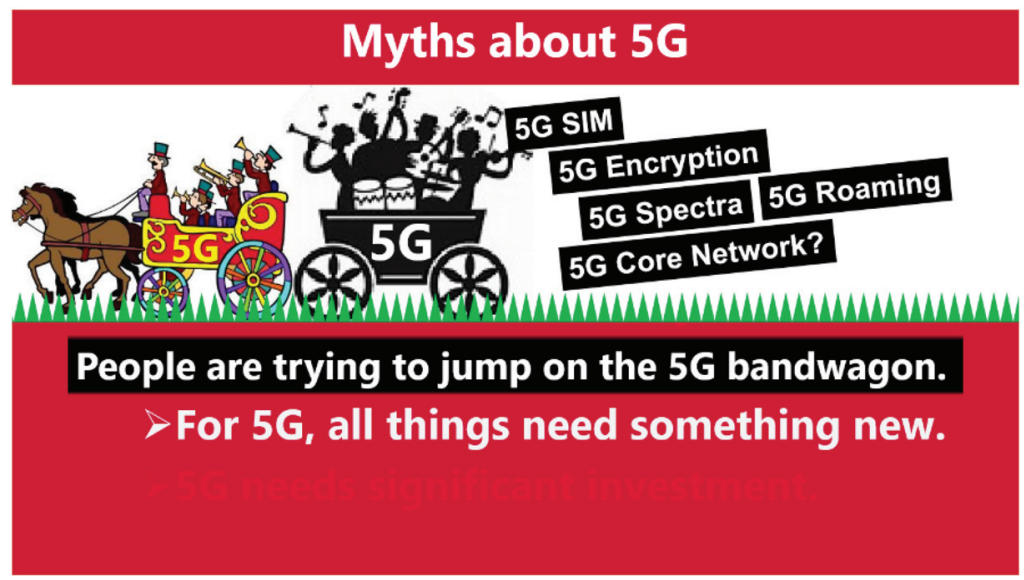

Figure 3 A Slide about $5 \mathrm{G}$ boom.

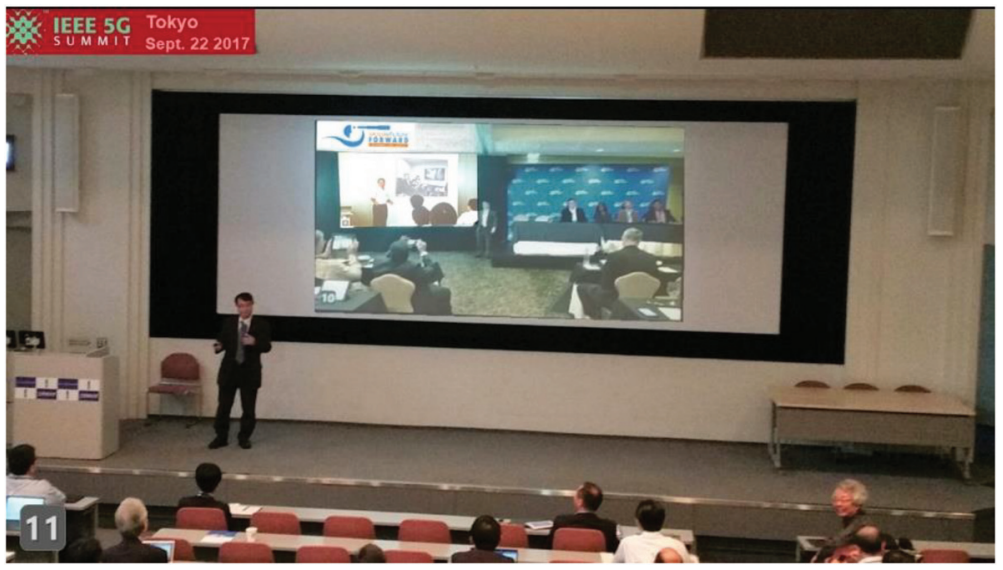

Figure 4 A picture at the IEEE 5G Summit Tokyo.

Originally the slide in Figure 3 was created to make people calm down. However, on the contrary, things went to the totally opposite direction. The 5G boom has continued to grow, and moreover, started involving other verticals. $5 \mathrm{G}$ has been attracting interest from a wide variety of industries. It is a good thing to have expanding business opportunities. Therefore, the author has changed the message of this slide. The new message is "Let's get on the 5G bandwagon." In addition to the three key features showing technical capabilities, the business aspect is another key feature as shown in Figure 5. In fact, DOCOMO has been collaborating with many partners in various 


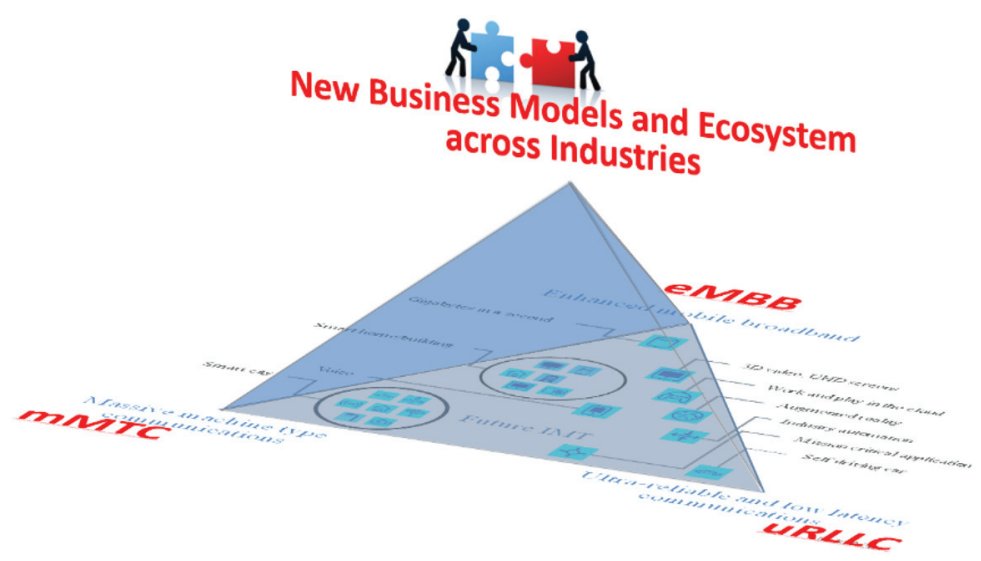

Figure 5 5G key features with a business aspect.

industries: automotive, railway, construction machinery, entertainment and so on. In the presentation, it was announced that DOCOMO launched " $5 \mathrm{G}$ Trial Sites' and has been actively working with partners in various industries.

\section{5G Economics}

There are concerns about 5G investment. Some newspaper articles say 5G needs huge investment. Although this may be beneficial for the growth of the whole industry, it worries operators. Increasing investment without a revenue growth is not good for operators. An analysis has concluded that few operators might be able to expect a return on their $5 \mathrm{G}$ investment and that substantial CAPEX and OPEX are likely to be required for cell densification with small cells [3].

People tend to believe that the launch of new generation technology will lead to huge investment. Figure 6 shows DOCOMO's CAPEX for the past 18 years. DOCOMO launched 3G and 4G LTE in 2001 and 2010 respectively. As shown in this figure, the launch of new generation technologies did not necessarily lead to a sharp ramp-up in investment.

The growth of data traffic volume is also shown in Figure 6 with a logarithmic scale while the CAPEX is shown with a linear scale. Several hundredor thousand-fold capacity increase was achieved with no increasing trend in CAPEX. Capacity enhancement with significant improvement in cost per bit is an unquestionable rationale for introducing new generation technologies 


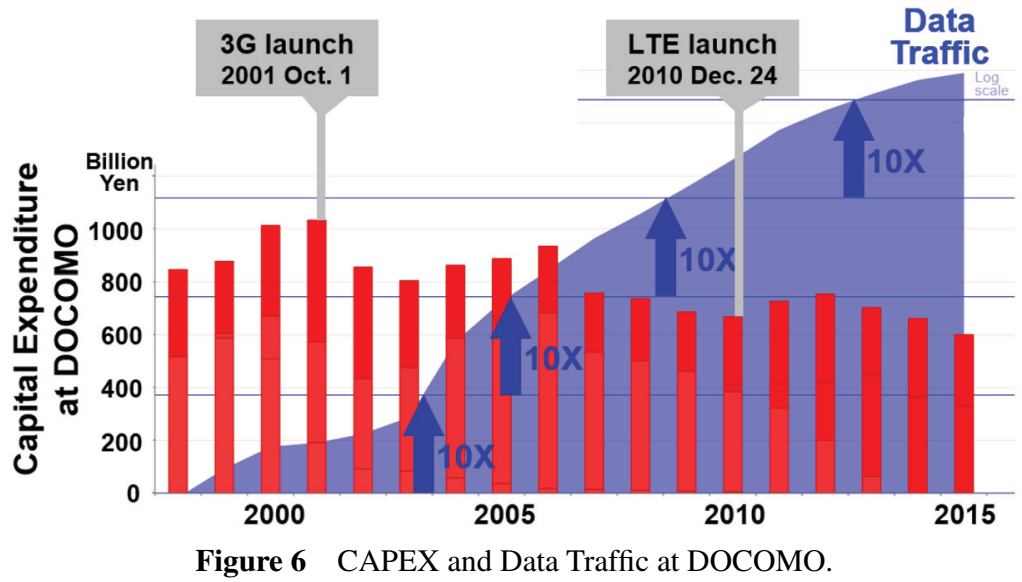

even when new services are uncertain. The data capacity enhancement with no upward trend in CAPEX can be one of the 5G killer services.

Most concerns come from a misunderstanding that $5 \mathrm{G}$ will use higher frequency bands such as millimetre waves and that it will result in a short coverage distance and a huge number of small cells. 5G will be deployed through the interworking between $5 \mathrm{G}$ new radio technology and enhanced LTE and with combinations of high and low frequency bands. $5 \mathrm{G}$ will not replace $4 \mathrm{G}$ systems overnight. $4 \mathrm{G}$ network equipment will be reused for $5 \mathrm{G}$ to the extent possible. Massive Multiple-Input Multiple-Output (Massive MIMO) will extend the coverage distance. Looking at such positive aspects, the author is encouraging the industry to tackle challenges to achieve a macro-cell based network even with millimetre waves.

\section{Future Predictions}

This section discusses two predictions in the form of laws defined by the author as a predictor based on observations of previous generations.

\subsection{Law of Previous Generations' Boom Just Before the Next}

The first law is the law of previous generations' boom just before the next generations. This means $4 \mathrm{G}$ regains popularity just before $5 \mathrm{G}$ launch. The phenomena of this law always happened in the previous generations. In the transition from 2G to 3G, Enhanced Data Rates for GSM Evolution (EDGE) 


\section{S. Onoe}

flourished just before 3G W-CDMA launch. It was said that W-CDMA would not penetrate because of EDGE.

In the transition from 3G to 4G, High Speed Packet Access Plus (HSPA+) or enhanced $3 \mathrm{G}$ was booming just before 4G LTE launch. In 2008, two years before LTE launch, an article of a telecom magazine described that LTE would cover all over the world, but a year later in 2009 it said that HSPA+ had emerged suddenly and that LTE had become a minority in its report of MWC.

The standardization was also active for HSPA evolution. The author's belief was that evolution of old technologies must be stopped after a new and better technology emerges. The author's negative campaign against HSPA+ saying that HSPA+ was a means for vendors to get money from operators was shown in the presentation with a scene from the video that happened to be recorded during the Q\&A in an MWC2009 event. The author's official reason to stop HSPA evolution is that it would make things complicated [4]. However

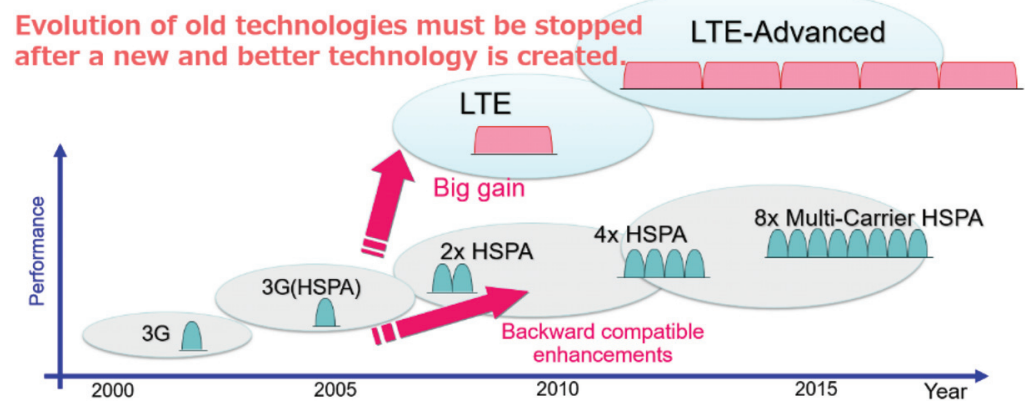

Figure 7 Evolution Path from $3 \mathrm{G}$ to $4 \mathrm{G}$.

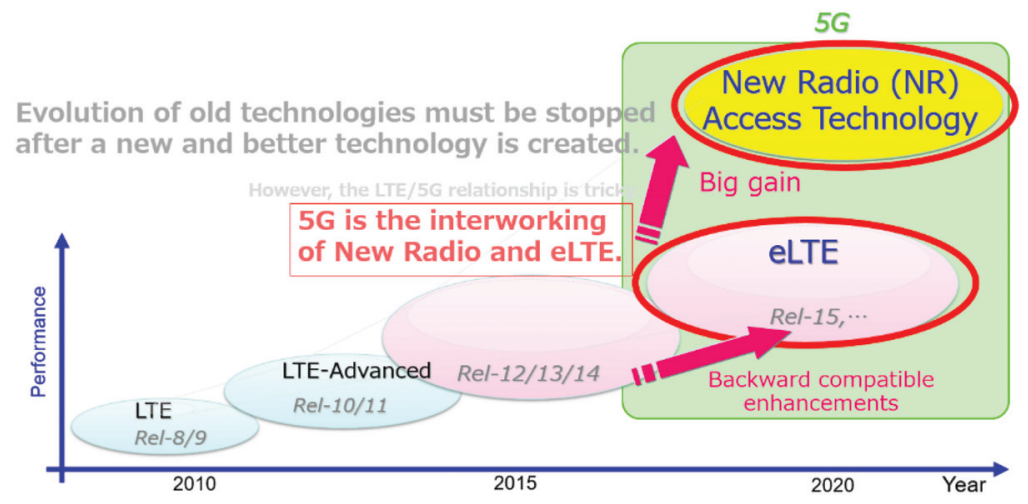

Figure 8 Evolution Path from $4 \mathrm{G}$ to $5 \mathrm{G}$. 
the standardization was continued and finally 8-carrier HSPA, which no one deployed, was specified in 3GPP as shown in Figure 7.

In general, the evolution of previous generations should be stopped after a new generation technology emerges. However, the $5 \mathrm{G}$ case is tricky, because $5 \mathrm{G}$ is based on the interworking of 5G New Radio and enhanced LTE as shown in Figure 8. In this transition, even if $4 \mathrm{G}$ regains popularity, the evolved $4 \mathrm{G}$ is likely to be called " $5 \mathrm{G}$ " as a marketing gimmick.

\subsection{Law of Great Success Only in Even-Numbered Generations}

The second law is the law of great success only in even-numbered generations shown in Figure 9.

$2 \mathrm{G}$ GSM was very successful as the first de-facto global standard. $4 \mathrm{G}$ LTE global deployment was remarkably quick while $3 \mathrm{G}$ deployment was relatively slow. As such, even-numbered generations, $2 \mathrm{G}$ and $4 \mathrm{G}$, had great success. Applying this law to 5G, the industry will need to wait until $6 \mathrm{G}$ to see all of its expectations for $5 \mathrm{G}$ fulfilled. In other words, $6 \mathrm{G}$ will be the complete form of $5 \mathrm{G}$, or $5 \mathrm{G}$ will be the final generation that will keep evolving ever after 2030.

This prediction was presented for the first time at an event in April, 2017. IEEE Spectrum reported the whole story of the event as given below [5].

High expectations for $5 \mathrm{G}$ were observed in the presentations at the event and speakers made grandiose statements about 5G. Such statements were punctuated by the author with the story of the law of great success. The author seemed to have a reputation for pouring cold water on $5 \mathrm{G}$. The reputation came from another article about $5 \mathrm{G}$ myths [6].

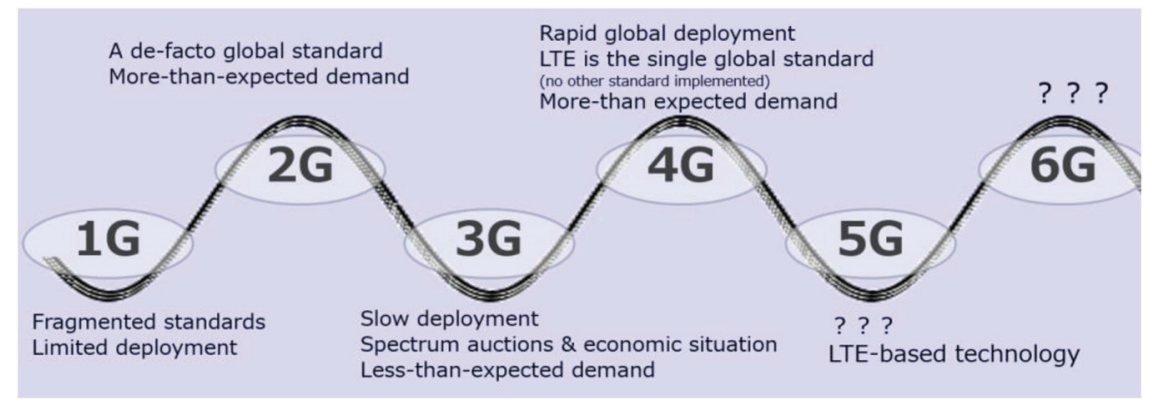

Figure 9 Law of Great Success Only in Even-Numbered Generations. 


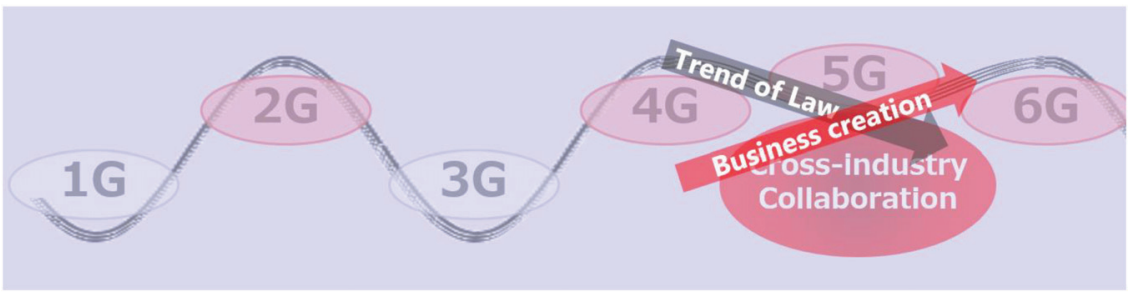

Figure 10 Key to a Great Success for $5 \mathrm{G}$ against Trend of Law.

The author did not intend to send a negative message. On the contrary, it was intended to be a positive message, asking the industry to be more realistic about the challenges it would face. The author made no statement to the effect that $3 \mathrm{G}$ was a failure nor $5 \mathrm{G}$ would be a failure or that they were not great successes but normal successes. The author emphasized that there must be something that would lift up 5G to a great success. Crossindustry collaboration will make $5 \mathrm{G}$ a great success against the downward trend predicted by the law as shown in Figure 10.

\section{Conclusion}

The history of mobile communications, what $5 \mathrm{G}$ will create and the economics of $5 \mathrm{G}$ were discussed. The author believes $5 \mathrm{G}$ will bring in favourable economics while there are still many concerns among operators. $5 \mathrm{G}$ will be successful definitely. To make $5 \mathrm{G}$ a great success rather than a normal success, cross-industry corroboration will be the key. $5 \mathrm{G}$ is now attracting interest from the wide variety of industries. This will create new opportunities for business and ecosystems. The paper concludes with a positive message: "Let's get on the $5 \mathrm{G}$ bandwagon together."

\section{References}

[1] S. ONOE, et al. "3G Evolution Scenario Toward 4G: Super 3G Concept," Wireless Communications and Mobile Computing, vol. 7, no. 8, October 2007, pp. 1013-1019. [Online]. Available at: http://onlinelibrary. wiley.com/doi/10.1002/wcm.511/pdf

[2] NTT DOCOMO, et al. "Proposed Study Item on Evolved UTRA and UTRAN," 3GPP, RP-040461, December 2004. [Online]. Available at: 
http://www.3gpp.org/ftp/TSG_RAN/TSG_RAN/TSGR_26/Docs/ZIP/RP_ 040461.zip

[3] Kim Kyllesbech Larsen, "The Economics of 5G." [Online]. Available at: https://www.slideshare.net/KimKyllesbechLarsen/the-economics-of-5g

[4] Martin Sauter, "MWC: Roundup," WirelessMoves. [Online]. Available at: https://blog.wirelessmoves.com/2009/02/mwc-roundup.html

[5] Amy Nordrum, "5G Progress, Realities Set in at Brooklyn 5G Summit," IEEE Spectrum, 21 April 2017. [Online]. Available at: https://spectrum. ieee.org/tech-talk/telecom/wireless/5g-progress-realities-set-in-at-brook lyn-5g-summit

[6] Amy Nordrum, "5 Myths About 5G," IEEE Spectrum, 25 May 2016. [Online]. Available at: https://spectrum.ieee.org/tech-talk/telecom/wirele ss/5-myths-about-5g

\section{Biography}

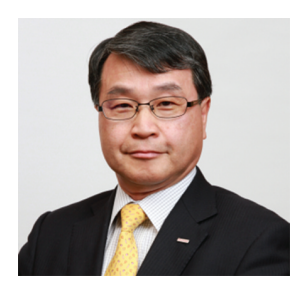

Seizo Onoe is President of DOCOMO Technology Inc. and Chief Technology Architect of NTT DOCOMO INC.

Prior to his current position, he was Chief Technology Officer, Executive Vice President and a Member of the Board of Directors of NTT DOCOMO from June 2012 to June 2017. He took various positions of Managing Director of R\&D organizations within NTT DOCOMO as Senior Vice President and Vice President from July 2002 to June 2012. He has been responsible for leading initiatives in the research and development of analog cellular systems (1G), digital cellular systems (2G), W-CDMA/HSPA (3G), LTE, LTE-Advanced (4G) and 5G. He has worked for NTT and NTT DOCOMO since 1982. He has a master's degree in electronics from the Kyoto University Graduate School of Engineering. 
